\title{
Detection of Tobacco streak virus isolates in North American Cranberry (Vaccinium macrocarpon Ait.)
}

\author{
A. Teifion Jones, Wendy J. McGavin, and Alison Dolan, Virology Unit, Division of \\ Pathology, Scottish Crop Research Institute, Invergowrie, Dundee DD2 5DA, Scotland, UK
}

Corresponding author: A. Teifion Jones.tjones@scri.sari.ac.uk

Jones, A. T., McGavin, W. J., and Dolan, A. 2001. Detection of Tobacco streak virus isolates in North American cranberry (Vaccinium macrocarpon Ait.). Online. Plant Health Progress doi:10.1094/PHP-2001-0717-01-RS.

\section{Abstract}

In tests on nine cranberry cultivars imported into Scotland from the USA, two cultivars, Pilgrim and AJ, were found infected with Tobacco streak virus (TSV). Three distinct isolates of this virus were detected in this infected material and were distinguished by their infection of, and reactions in, different herbaceous test plants. This is the first report of natural infection with TSV in Vaccinium species and the first characterised virus reported in cranberry. As TSV is seed and pollen transmitted in many hosts, care should be taken to test plants before propagation or when using as parents in plant breeding programs.

\section{Introduction}

Several species of cultivated Vaccinium are reported to be infected naturally with 14 or more virus or virus-like agents, some of which induce noticeable disease symptoms and decrease productivity $(2,4)$. Almost all such records have been made on low ( $V$. angustifolium Ait.) and high (V. corymbosum L. and $V$. australe Small) bush and rabbit eye (V. ashei Reade) blueberries (4). Only two virus diseases are reported to occur naturally in cranberry (Vaccinium macrocarpon Ait.) (4). Based on electron microscopy of ultrathin sections of infected plants, one virus has been tentatively identified as being similar to Blueberry red ringspot virus, a caulimovirus (K. S. Kim, in 5), but no viruses have been characterised from diseased cranberry. In the course of indexing for virus infection of cranberry cultivars imported from North America, mechanically transmissible viruses were detected in some of these imported cranberry sources. All virus isolates were found to be Tobacco streak virus(TSV) but they differed from one another in symptomatology and host range in herbaceous test plants. This paper describes these studies.

\section{Plant Sources and Experimental Protocols}

Nine cultivars of cranberry were imported into the Scottish Crop Research Institute (SCRI) under a Plant Phytosanitary certificate from North America and held in quarantine glasshouse facilities pending results of tests for pests and pathogens. To test for mechanically transmissible viruses, pooled leaf samples from individual trays of each cultivar were extracted in a small volume of $2 \%$ nicotine solution in a pestle and mortar. The resulting extract was inoculated immediately to leaves or cotyledons of young plants of Chenopodium quinoa, Cucumis sativus, and Nicotiana clevelandii, dusted previously with corundum powder to act as an abrasive. A few minutes after inoculation, the inoculated leaves were rinsed with water and then covered with paper for 12-16h. Virus isolates recovered in this way were then maintained in herbaceous plants, usually $C$. quinoa and $N$. clevelandii. Reference samples of these virus isolates were freeze-dried in herbaceous tissues and stored at $-15^{\circ} \mathrm{C}$.

For host range studies in herbaceous plants, leaves of Nicotiana species infected with the individual virus cultures were extracted in $0.01 \mathrm{M}$ phosphate buffer, $\mathrm{pH} 7$, containing $0.2 \%$ thioglycerol and manually inoculated to corundum-dusted plants. All plants were maintained in an insect-proof glasshouse at ca. 18$20^{\circ} \mathrm{C}$. To determine infection in these test plants, extracts from inoculated and uninoculated leaves of each plant were inoculated separately to C. quinoa test plants that were then observed for virus symptoms.

Serological tests were made in $0.7 \%$ agarose gels containing $0.85 \% \mathrm{NaCl}$ and $0.02 \%$ sodium azide using 7-mm diameter wells spaced $4 \mathrm{~mm}$ apart. Virus antigen was in leaf sap extracts, usually of infected $N$. benthamiana. Virus antiserum was either from stocks held at SCRI or that kindly supplied from colleagues elsewhere.

\section{Virus Isolation and Virus Properties}

Sap inoculation tests to herbaceous test plants were made from the following cranberry cultivars: AJ, Ben Lear, Crowley, Early Black, Franklin, McFarlin, Pilgrim, Stevens, and Wilcox. In such assays, symptoms developed in test plants when inoculated with extracts from only cvs Pilgrim and AJ. Further studies showed that separate trays of cv. Pilgrim contained virus isolates that differed in herbaceous host 
range and symptomatology and each differed from the isolate present in cv. AJ (Table 1). The two isolates from cv. Pilgrim differed in the severity of the symptoms they induced in some herbaceous test plants and were designated Pilgrim mild (PM) and Pilgrim severe (PS) and that from cv. AJ as AJ.

Table 1. Comparative herbaceous host range and symptomatology of three Tobacco streak virus isolates from cranberry.

\begin{tabular}{|l|l|l|l|}
\hline \multirow{2}{*}{ Plant species } & \multicolumn{3}{|c|}{ Virus isolate: } \\
\cline { 2 - 4 } & \multicolumn{1}{|c|}{ PS } & \multicolumn{1}{|c|}{ PM } & \multicolumn{1}{|c|}{ AJ } \\
\hline Chenopodium amaranticolor & Lnl; Sm, Se & Lnl; Sm & Lcl; Se \\
\hline C. murale & Lnl; Se; Sn & Lnl; not S & Lnl; not S \\
\hline C. quinoa & Lnl; Sn & Lnl; Sn & Lnl; slow Sn \\
\hline Cucumis sativus cv. Venlo Pickling & Lcl; S & Lcl; not S & Lcl; not S \\
\hline Nicotiana benthamiana & L; S & Sm, stunted & Lnr; Se \\
\hline N. clevelandii & stunted S & stunted S & Lnl; Sn \\
\hline N. debnyii & stunted S & Lcl; Sn & Lnl; Sn \\
\hline N. glutinosa & L; Scm & Lnr; not S & Lnr; S \\
\hline N. occidentalis 37B & Lnl; Sns & Lnl; Sns & Lnl; Sn \\
\hline N. tabacum cv. Samsun & Lnl; Sm & L; not S & L; Sn \\
\hline N. tabacum cv. White Burley & Lnl; Sm & L; Sns & Lnr; S \\
\hline N. tabacum cv. Xanthi-nc & Lnl; Sns & L; not S & Lnr; Sn \\
\hline Phaseolus vulgaris cv. The Prince & Lnl; not S & Lnl; not S & Lnl; not S \\
\hline
\end{tabular}

$\mathbf{L}=$ symptomless infection in inoculated leaves; $\mathbf{L c l}=$ local chlorotic lesions; $\mathbf{L n I}=$ local necrotic lesions; $\mathbf{L n r}=$ local necrotic rings; $\mathbf{S}=$ symptomless infection of uninoculated leaves; $\mathbf{S c m}=$ systemic chlorotic mottle; $\mathbf{S e}=$ systemic epinasty; $\mathbf{S m}=$ systemic mottle; $\mathbf{S n}=$ systemic necrosis; $\mathbf{S n s}=$ systemic necrotic spots.

Table 1 shows the comparative herbaceous host range and symptomatology of these three different virus isolates. All 13 species listed were infected with each virus isolate but only isolate AJ induced leaf symptoms in all species and, of these, only 11 species were infected systemically. Isolate PM infected seven species systemically, whereas isolate PS infected 12 species systemically. The three virus isolates were therefore readily distinguishable in these tests.

When the virus isolates in sap of infected $N$. benthamiana were tested in agarose gel double diffusion serological tests, they failed to react with antiserum to the following viruses: Blueberry leaf mottle, Peach rosette mosaic, Tobacco ringspot (New Jersey ringspot strain), and Tomato ringspot (isolates, West Virginia, Staff, Chickadee and Elder). However, each virus isolate reacted with antiserum to isolates of Tobacco streak virus (TSV) from strawberry (SC; from cv. Sweet Charlie), red raspberry (RR) and tobacco (HF, the type isolate (1)) in the USA. In further tests, each virus isolate was placed adjacent to one another and to each of two other TSV isolates (SC, and AN from red raspberry) and tested against the three TSV antisera listed above. In these tests against antiserum to isolate RR, the precipitin line formed against isolate SC spurred over that produced by each of the other virus isolates indicating that it differed serologically from them. However, in tests against antiserum to isolates SC and HF, the precipitin lines of all virus isolates were confluent indicating that in these tests the isolates were serologically indistinguishable.

\section{Conclusions and Recommendations}

This is the first report of TSV in Vaccinium species and the first characterised virus described from cranberry. TSV is the type member of the virus genus Ilarvirus and, although this is the first report of it in Vaccinium,Blueberry shock virus, another but distinct virus in the genus Ilarvirus, has been reported in blueberries in the Pacific Northwest of North America (3). TSV is seed-transmitted, often to a high incidence in plants, and is known to be pollen-transmitted in some species, infecting both the seed resulting from fertilisation and the plant bearing the seed (1). It is not known if this occurs in cranberry or whether infection affects plant growth and yield. However, in view of its detection in cranberry planting material, it would be prudent to routinely test material for TSV infection before propagation and before using as parents in plant breeding programs.

\section{Acknowledgement}

We thank R. R. Martin for the gift of antiserum to the TSV isolate from red raspberry (RR). 


\section{Literature Cited}

1. Fulton, R. W. 1985. Tobacco streak virus. Association of Applied Biologists Descriptions of Plant Viruses No. 307.

2. Guy, G. L. 1993. Virus and virus like diseases of Vaccinium and the safe movement of germplasm into Australia. Acta Horticulturae 346: 260-264.

3. MacDonald, S. G., Martin, R. R., and Bristow, P. R. 1991. Characterization of an ilarvirus associated with a necrotic shock reaction in blueberry. Phytopathology 81: 210-214.

4. Ramsdell, D. C., Hancock, J. F., and Stretch, A. W. 1987. Virus and virus-like diseases of Vaccinium (blueberry and cranberry). Pages 101-126 in: Virus Diseases of Small Fruits. R. H. Converse, ed. USDA Agriculture Handbook No. 631.

5. Stretch, A. W. 1987. Ringspot of cranberry. Pages 123-124 in: Virus Diseases of Small Fruits. R. H. Converse, ed. USDA Agriculture Handbook No. 631. 